\title{
Interfacial Microstructure between Copper Ribbon and Nickel-coated Copper Plate Formed by Ultrasonic Bonding*
}

\author{
by Masakatsu Maeda**, Daisuke Yagi*** and Yasuo Takahashi**
}

\begin{abstract}
The present paper reports the bondabiliy and the interfacial microstructure between copper ribbons and nickel-coated copper plates by ultrasonic bonding. The ultrasonic bondability of copper to nickel is significantly improved by heating up to $423 \mathrm{~K}$. On the other hand, the bondability of copper to itself is deteriorated by surface oxidation. It is also shown that the nickel coating suppresses the deterioration. The nickel layer at the central part of the bond area shows S-curved morphology, whereas it is torn and/or folded in the peripheral part of the bond interface, indicating that a complicated deformation is induced during bonding. Although ultrasonic bonding at $423 \mathrm{~K}$ allows lowering of the ultrasonic power to one-third of that required for bonding at room temperature, it is difficult to avoid tearing of the Ni layer.
\end{abstract}

Key Words: Ultrasonic bonding, Electronics packaging, Interfacial microstructure, $\mathrm{Cu}, \mathrm{Ni}$, Oxidation protection coating, Surface oxide

\section{Introduction}

Major part of power cables, patterns on circuit boards and interconnections on integrated circuit chips of today is made of copper $(\mathrm{Cu})$. High electrical and thermal conductivity and high strength makes $\mathrm{Cu}$ the irreplaceable material for electric power and signal transmission. However, gold and aluminum alloys are commonly used instead of $\mathrm{Cu}$ as bonding wires which connect semiconductor devices to outer circuits. Thus, $\mathrm{Cu}$ wire bonding technology has been strongly demanded for long time. One of the crucial reasons hindering $\mathrm{Cu}$ from the application to bonding wires is the difficulty in bonding at low temperatures ${ }^{1-3)}$.

It is known that native surface oxides of $\mathrm{Cu}$ deteriorate the bondability ${ }^{2,4)}$. $\mathrm{Cu}$ forms oxide film on its surface by exposure to ambient air. To make things worse, $\mathrm{Cu}$ surface is not passivated by the formation of the oxide film, i.e., the film keeps growing by exposure to ambient air. To prevent the surface oxidation, the surface coating by tin $(\mathrm{Sn})$ or nickel $(\mathrm{Ni})$ is known to be effective. Although Ni is harder than Sn indicating that it is difficult to bond by solid-state bonding process ${ }^{5-7)}$, Ni has a great advantage to $\mathrm{Sn}$. $\mathrm{Ni}$ does not form intermetallic compound with $\mathrm{Cu}$, whereas $\mathrm{Sn}$ does ${ }^{8)}$. Thus, $\mathrm{Ni} / \mathrm{Cu}$ interface does not deteriorate by formation of intermetallic compounds. To savor this advantage, ultrasonic bonding technology of $\mathrm{Cu}$ with $\mathrm{Ni}$-coated $\mathrm{Cu}$ is needed.

The present study aims to clarify the following two points. One is the ultrasonic bondability between $\mathrm{Cu}$ and $\mathrm{Ni}$ including the effects of the bonding temperature and exposed time to air after surface cleaning. The other point to clarify is the interfacial

\footnotetext{
*Received: 2012.11.28

${ }^{* *}$ Member, Joining and Welding Research Institute, Osaka University

${ }^{* * *}$ Non-member, Graduate School of Engineering, Osaka University
}

microstructure formed by ultrasonic bonding. Recently, Maeda et al. reported that interfacial microstructures formed by ultrasonic bonding of $\mathrm{Cu}$ ribbons to $\mathrm{Sn}$-coated $\mathrm{Cu}$ plates reveal complicated deformation of the materials during bonding ${ }^{3)}$. Whether the same deformation occur with $\mathrm{Ni}$-coated samples is to be clarified.

\section{Experimental procedure}

Three types of substrates were prepared, namely $\mathrm{Cu}, \mathrm{Ni}$ and $\mathrm{Ni} / \mathrm{Cu}$ substrates. $\mathrm{Cu}$ substrates were $0.6-\mathrm{mm}$-thick $\mathrm{Cu}$ plates of which nominal purity was $99.99 \%$. Ni substrates were $0.1-\mathrm{mm}$ thick $\mathrm{Ni}$ plates of which nominal purity was $99 \% \mathrm{Ni} / \mathrm{Cu}$ substrates were $2-\mu \mathrm{m}$-thick $\mathrm{Ni}$ films electroplated on 0.3 -mm-thick $\mathrm{Cu}$ plates. On the other hand, $\mathrm{Cu}$ ribbons were prepared by cold rolling of $\mathrm{Cu}$ substrates to a thickness of $0.1 \mathrm{~mm}$ and cutting into a 1.0-mm-wide 5.0-mm-long rectangular shape. Cu substrates, $\mathrm{Ni}$ substrates and $\mathrm{Cu}$ ribbons were annealed at 773,1073 and $773 \mathrm{~K}$, respectively, for $900 \mathrm{~s}$ in vacuum of $1.0 \times 10^{-3} \mathrm{~Pa}$. Then, they were immersed into diluted nitric acid for $180 \mathrm{~s}$ to remove surface oxide layers on them. Some of them were exposed to air for 864 ks after the acid cleaning, of which surface are expressed as "the exposed surface" in the following text. The other samples except the $\mathrm{Ni} / \mathrm{Cu}$ substrates were subjected to bonding immediately after the acid cleaning (within $600 \mathrm{~s}$ ), of which surface are expressed as "the fresh surface". The $\mathrm{Ni} / \mathrm{Cu}$ substrates were supplied by a manufacturer and thus they were inevitably exposed to air for a long time. Since the thickness of the electroplated $\mathrm{Ni}$ layer became ununiform by acid cleaning, the $\mathrm{Ni} / \mathrm{Cu}$ substrates were subjected to bonding only in as-supplied state, i.e., without acid cleaning.

The substrates were fixed on the stage of the ultrasonic bonding apparatus. The $\mathrm{Cu}$ ribbon was laid on the substrate with its longitudinal direction parallel to the direction of ultrasonic 
vibration. The ribbon was pressed to the substrate with a wedgetool and then vibrated parallel to the interface for $500 \mathrm{~ms}$. The ultrasonic frequency of the apparatus was $75.0 \mathrm{kHz}$. The ultrasonic power $(P)$ and the bonding force $(F)$ were varied in the range of $10.0 \leq P / \mathrm{W} \leq 40.0$ and $3.9 \leq F / \mathrm{N} \leq 30.1$, respectively. The bonding temperature $(T)$, represented by the temperature of the heater-embedded ultrasonic bonding stage, was set at room temperature or at $423 \mathrm{~K}$. In both temperatures, bonding was carried out in ambient air without shielding gas.

The interfacial microstructures of the joints were analyzed by scanning electron microscopy. Back-scattered electron imaging mode was used to observe compositional change as the contrast.

\section{Results and discussion}

Fig. 1 shows the ultrasonic bondability diagram for freshsurfaced $\mathrm{Cu}$ ribbons and exposed $\mathrm{Ni} / \mathrm{Cu}$ substrates. The areas colored with dark and bright gray depict the ranges of ultrasonic power and bonding force in which bonds can be obtained by ultrasonic bonding at room temperature and at $423 \mathrm{~K}$, respectively. Two important points are noticed in the figure. One is that the condition range of successful bonding is not sensitive to the bonding force, whereas it is very sensitive to the ultrasonic power. At ultrasonic power lower than the appropriate range, the bonding fails due to insufficient interfacial adhesion. On the other hand, ultrasonic power higher than the range results in failure due to the fracture of the $\mathrm{Cu}$ ribbon. The other point is that considerably high ultrasonic power and bonding force are required to bond $\mathrm{Cu}$ ribbons with $\mathrm{Ni} / \mathrm{Cu}$ substrates at room temperature, whereas they are significantly reduced to one-third of that required at room temperature by heating the specimens up to $423 \mathrm{~K}$. It is also noted that the condition range for successful bonding is narrow at room temperature, whereas it is broadened by heating up to $423 \mathrm{~K}$.

Fig. 2 shows a cross-sectional bond interface between a $\mathrm{Cu}$ ribbon and a $\mathrm{Ni}$ substrate bonded under the condition of $26.5 \mathrm{~N}$, $30.0 \mathrm{~W}$ at room temperature. Both surfaces of the $\mathrm{Cu}$ ribbon and the Ni substrate were fresh. The bonding condition was selected

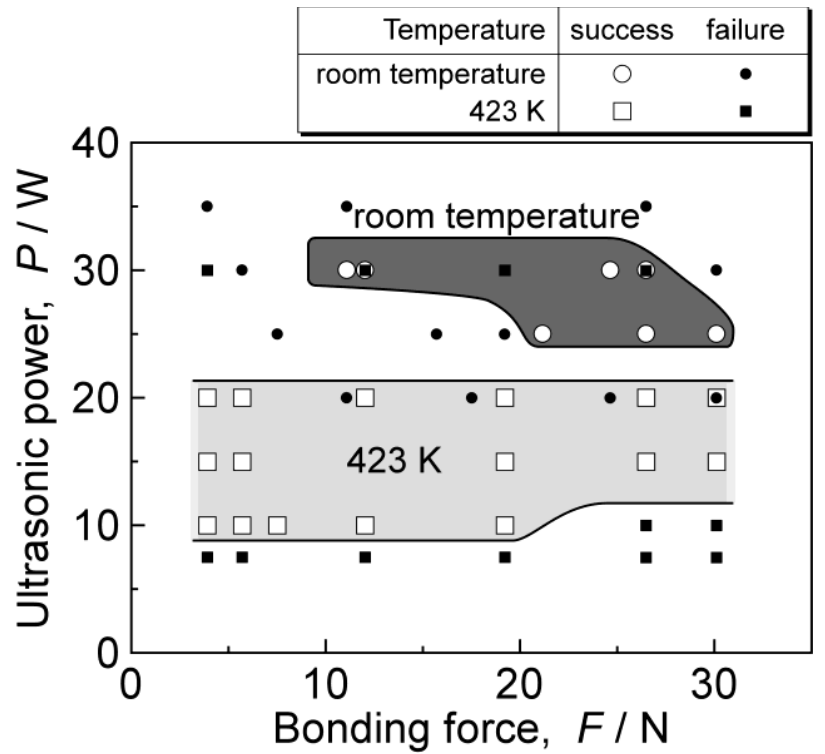

Fig. 1 Bondability of fresh-surfaced $\mathrm{Cu}$ ribbons and exposed $\mathrm{Ni} / \mathrm{Cu}$ substrates for ultrasonic bonding at room temperature and at $423 \mathrm{~K}$.

as the optimum for bonding at room temperature on the basis of the bondability shown in Fig. 1. The micrograph of the entire bond shown in Fig. 2(a) indicates that a wide area of $600 \mu \mathrm{m}$ is adhered firmly. No included particles are observed at the interface even by high-magnification observation shown in Fig. 2(b). The interface appears flat.

However, the interfacial microstructure becomes different by exposing the Ni substrate to air for 864 ks after the acid cleaning. Fig. 3 shows an interface of a fresh-surfaced $\mathrm{Cu}$ ribbon and an exposed Ni substrate bonded under the same condition with that shown in Fig. 2. The entire bond shown in Fig. 3(a) indicates that the length of the bonded area becomes $348 \mu \mathrm{m}$, which is only a half of that formed with fresh surfaces. This result indicates that the bondability is deteriorated by exposing the Ni substrate to air for long time. The peripheral part of the bond interface appears wavy, as depicted in Fig. 3(b). The microstructure suggests that both $\mathrm{Cu}$ and $\mathrm{Ni}$ have deformed locally under a non-uniform and complicated stress during bonding. The microstructure is considered that it is in a preliminary stage of that observed at the

(a)
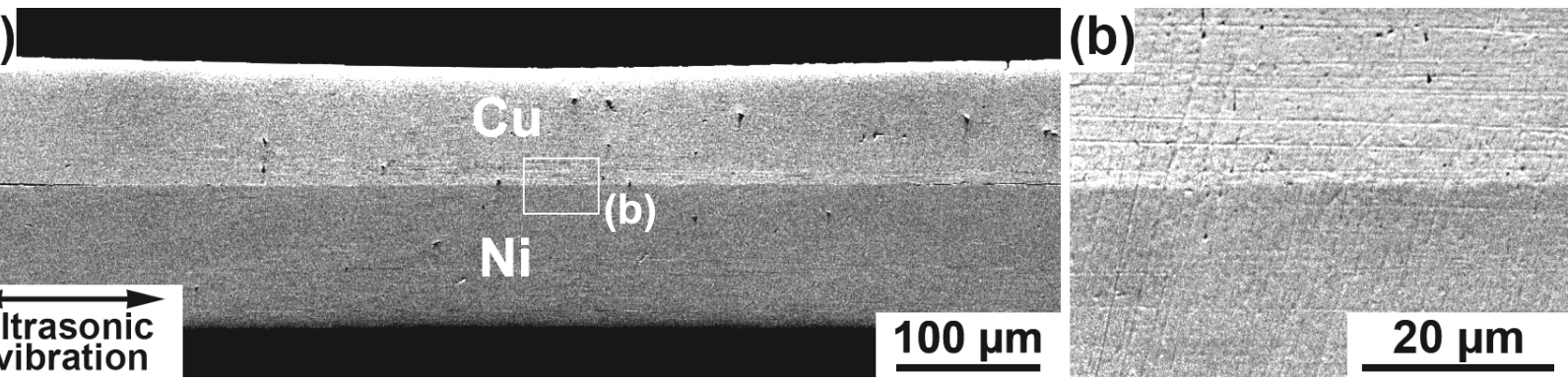

Fig. 2 Interfacial microstructure of a Cu ribbon and a Ni substrate bonded under the condition of $26.5 \mathrm{~N}, 75.0 \mathrm{kHz}, 30.0 \mathrm{~W}, 500 \mathrm{~ms}$ at room temperature. Both surfaces of the $\mathrm{Cu}$ ribbon and the Ni substrate were fresh. (a) Appearance of the entire bond; (b) magnified central bond area marked in Fig. 2(a). 
(a)
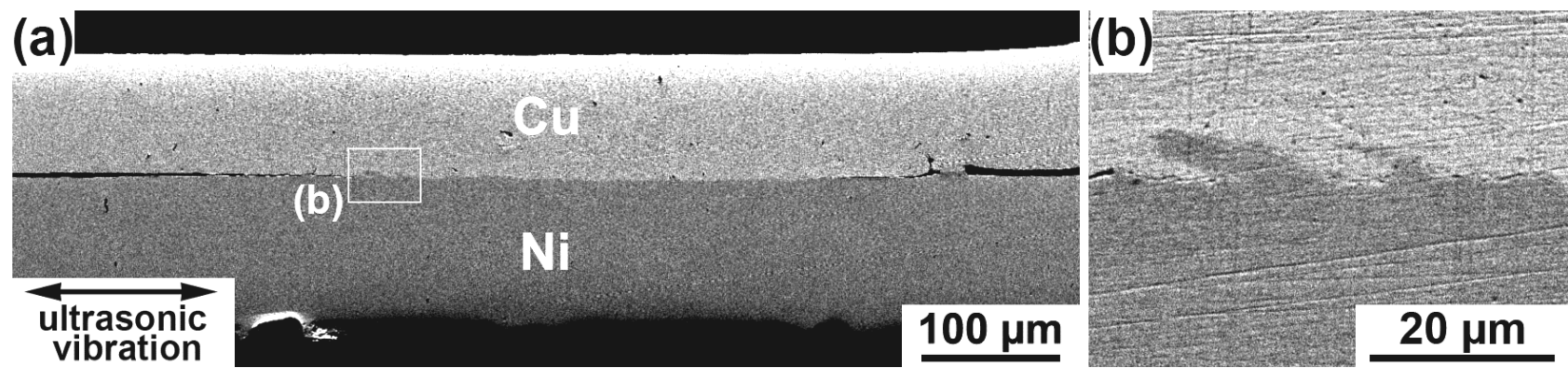

Fig. 3 Interfacial microstructure of a fresh-surfaced $\mathrm{Cu}$ ribbon and an exposed Ni substrate bonded under the condition of $26.5 \mathrm{~N}, 75.0 \mathrm{kHz}, 30.0 \mathrm{~W}, 500$ ms at room temperature. (a) Appearance of the entire bond; (b) magnified peripheral bond area marked in Fig. 3(a).

ultrasonic bonded interfaces between $\mathrm{Cu}$ ribbons and $\mathrm{Sn}$-coated $\mathrm{Cu}$ plates ${ }^{3)}$. On the other hand, $\mathrm{Cu}$ and $\mathrm{Ni}$ are adhered intimately showing no inclusion between them.

Although the bondability of exposed surfaces of Ni show a distinct deterioration, it is better than that of exposed surfaces of $\mathrm{Cu}$. The exposure of $\mathrm{Cu}$ ribbons to air for $864 \mathrm{ks}$ makes all bonding conditions employed in the present study fail to bond even if the Ni substrates just after acid cleaning are used. Thus, the deterioration of bondability by exposure to air is more significant with $\mathrm{Cu}$ surface than that with $\mathrm{Ni}$ surface. Ni-coating of $\mathrm{Cu}$ surface is effective for suppressing the deterioration.

Fig. 4 shows an interface of a fresh-surfaced $\mathrm{Cu}$ ribbon and an exposed $\mathrm{Ni} / \mathrm{Cu}$ substrate bonded under the condition of $12.0 \mathrm{~N}$, $30.0 \mathrm{~W}$ at room temperature. This condition is near the minimum bonding force for ultrasonic bonding at room temperature as shown in Fig. 1. The entire bond interface shown in Fig. 4(a) reveals that the length of the bond area is $199 \mu \mathrm{m}$, being one-third of that formed with fresh surfaces at the optimum condition shown in Fig. 2. Although the bondability of $\mathrm{Ni}$ is deteriorated by

\section{(a)}
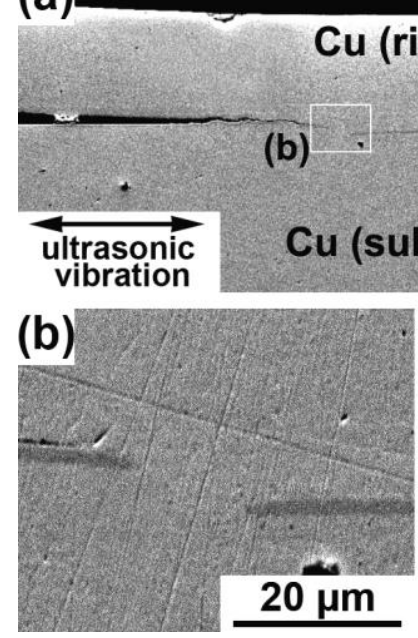

\section{Cu (ribbon)}

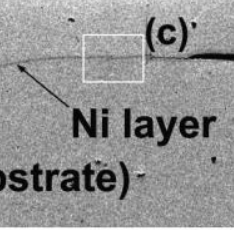

$100 \mu \mathrm{m}$

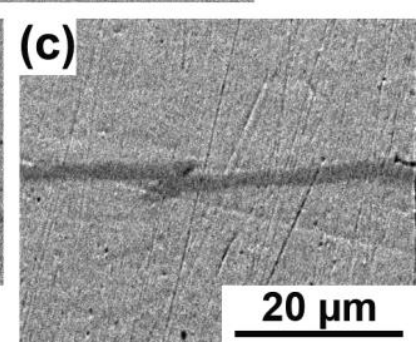

Fig. 4 Interfacial microstructure of a fresh-surfaced $\mathrm{Cu}$ ribbon and an exposed $\mathrm{Ni} / \mathrm{Cu}$ substrate bonded under the condition of $12.0 \mathrm{~N}, 75.0 \mathrm{kHz}$, $30.0 \mathrm{~W}, 500 \mathrm{~ms}$ at room temperature. (a) Appearance of the entire bond; (b) and (c) magnified peripheral bond areas marked in Fig. 4(a). exposure to air for considerably long time, it is demonstrated that $\mathrm{Cu} / \mathrm{Ni}$ substrates can still form bonds. The $\mathrm{Ni}$ layer at the interface appears in S-curved shape. The layer is bent toward the substrate in the left side of the bond area and toward the ribbon in the right side. In addition, the Ni layer in the left side is torn as shown in Fig. 4(b), where the Cu ribbon is directly bonded to the $\mathrm{Cu}$ substrate under the Ni layer. On the other hand, the layer is folded in the right side of the interface.

The torn Ni layer suggests that a considerable stress is applied to the layer during ultrasonic bonding. In electronics packaging, such a high stress is not preferred, since it will damage the device structure under the electrode pad. Therefore, it is required to
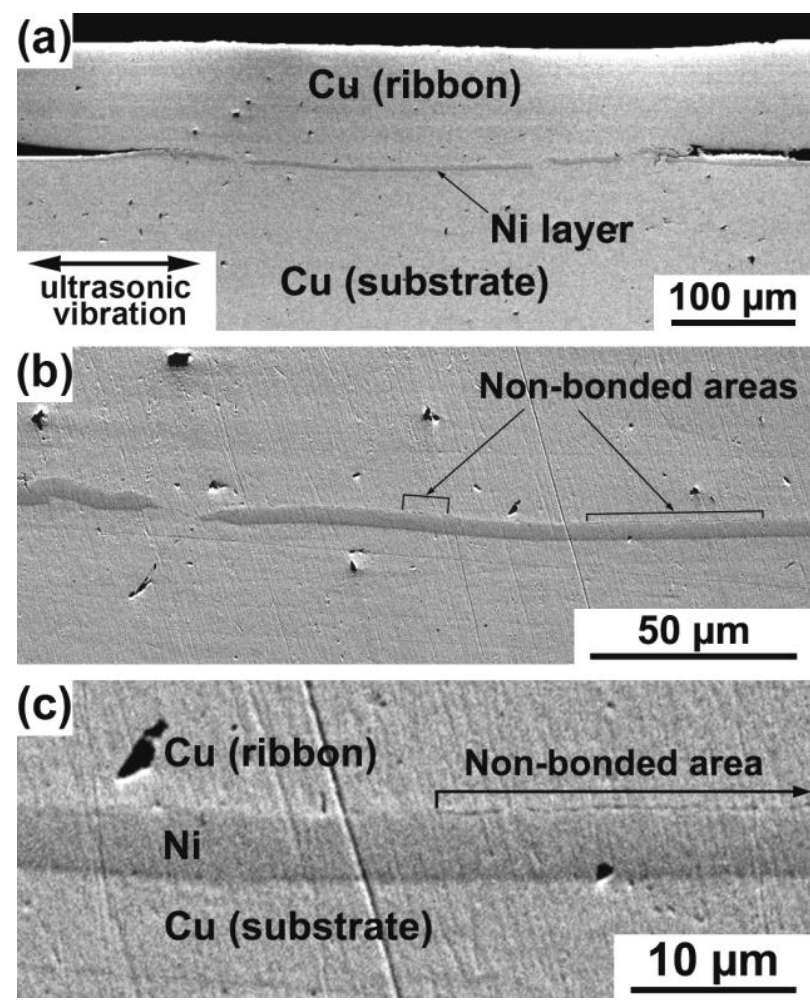

Fig. 5 Interfacial microstructure of a fresh-surfaced $\mathrm{Cu}$ ribbon and an exposed $\mathrm{Ni} / \mathrm{Cu}$ substrate bonded under the condition of $5.7 \mathrm{~N}, 75.0 \mathrm{kHz}$, $10.0 \mathrm{~W}, 500 \mathrm{~ms}$ at $423 \mathrm{~K}$. (a) Appearance of the entire bond; (b) enlarged left-half bond area of (a); (c) further enlargement showing an interface between bonded and non-bonded areas. 
reduce the stress by lowering the ultrasonic power. As shown in Fig. 1, it is effective to preheat the substrate and the ribbon to achieve bonding under low ultrasonic power.

Fig. 5 shows an interface of a fresh-surfaced $\mathrm{Cu}$ ribbon and an exposed $\mathrm{Ni} / \mathrm{Cu}$ substrate bonded under the condition of $5.7 \mathrm{~N}$, $10.0 \mathrm{~W}$ at $423 \mathrm{~K}$. By heating up to $423 \mathrm{~K}$, the ribbon and the substrate can be bonded under a low ultrasonic power of $10 \mathrm{~W}$. The length of the bond area is $369 \mu \mathrm{m}$, as shown in Fig. 5(a). It is wider than that shown in Fig. 4, even though some parts in the bond area are found non-bonded, as marked in Fig. 5(b) and depicted in Fig. 5(c). However, the Ni layer shown in Fig. 5(a) is torn at three points, suggesting that the ultrasonic power of $10 \mathrm{~W}$ is still high for the damage suppression.

Although it will be possible to lower the ultrasonic power by raising the temperature further, it is not appropriate for electronics packaging. A hint to avoid tearing and folding of the Ni layer is seen in Fig. 2 in which the interface remains flat even though the ultrasonic power is high. However, the mechanism and criteria to retain the interface flat is still unclear.

\section{Conclusions}

Ultrasonic bonding of $\mathrm{Cu}$ ribbons to Ni-coated $\mathrm{Cu}$ substrates were carried out to investigate the bondabiliy and the interfacial microstructure. The following points are made clear.

1. A considerably high ultrasonic power is required to bond $\mathrm{Cu}$ ribbons with $\mathrm{Ni} / \mathrm{Cu}$ substrates at room temperature. However, the required ultrasonic power is significantly lowered by heating the specimens up to $423 \mathrm{~K}$. Heating to $423 \mathrm{~K}$ also broadens the condition range of ultrasonic power and bonding force for successful bonding.

2. The condition range of successful bonding is not sensitive to the bonding force, whereas it is very sensitive to the ultrasonic power.

3. Bonding of fresh surfaces forms a wide and flat interface free of inclusions. Exposed surface of $\mathrm{Cu}$ makes failure of bonding at all conditions employed in the present study, whereas exposed surface of $\mathrm{Ni}$ allows bonding. However, the Ni layer is deformed anomalously (i.e., torn and/or folded) at the periphery of the bond area.

4. Lowering of the ultrasonic power by bonding at $423 \mathrm{~K}$ is still insufficient for prevention of the anomalous deformation.

\section{Acknowledgments}

The present study has been carried out under the support from the Japan Society for Promotion of Science through Grants-inAid for Scientific Research (project No. 18206076).

\section{References}

1) Z. W. Zhong: "Overview of wire bonding using copper wire or insulated wire," Microelectron. Reliab., 51 (2011), 4-12.

2) T. Uno: "Enhancing bondability with coated copper bonding wire," Microelectron. Reliab., 51 (2011), 88-96.

3) M. Maeda, T. Sato, N. Inoue, D. Yagi and Y. Takahashi: "Anomalous microstructure formed at the interface between copper ribbon and tin-deposited copper plate by ultrasonic bonding," Microelectron. Reliab., 51 (2011), 130-136.

4) M. Maeda, N. Inoue, T. Sato and Y. Takahashi: "Early stage of solid state interfacial reaction between copper and tin," Defect Diffus. Forum, 283-286 (2009), 323-328.

5) Y. Takahashi and K. Inoue: "Recent void shrinkage models and their applicability to diffusion bonding," Mater. Sci. Technol., 8 (1992), 953-964.

6) K. Nishiguchi and Y. Takahashi: "A quantitative analysis of solid state bonding process based on fundamental bonding mechanisms (part I) -modeling and numerical analysis of bonding process-," Quart. J. Jpn. Weld. Soc., 3 (1985), 303-309.

7) Y. Takahashi: "Numerical modeling of solid state bonding based on fundamental bonding mechanisms ---for bonding between dissimilar materials---," Ceram. Trans., 138 (2003), 29-47.

8) Binary Alloy Phase Diagrams, 2nd edition plus updates on CD-ROM, edited by T. B. Massalski, H. Okamoto, P. R. Subramanian, and L. Kacprzak, ASM International, Materials Park, Ohio, USA, (1996). 